Article

\title{
Phenolic Profiles and Antioxidant Activity of Lotus Root Varieties
}

\author{
Yang Yi ${ }^{1,2}$, Jie Sun ${ }^{1}$, Jun Xie ${ }^{1}$, Ting Min ${ }^{1,2}$, Li-Mei Wang ${ }^{2,3}$ and Hong-Xun Wang ${ }^{1,2, *}$ \\ 1 College of Food Science \& Engineering, Wuhan Polytechnic University, Wuhan 430023, China; \\ yiy86@whpu.edu.cn (Y.Y.); qiqijiayuguan@163.com (J.S.); 15927583334@163.com (J.X.); \\ minting1323@163.com (T.M.) \\ 2 Hubei Engineering Research Center for Fresh Food, Wuhan 430023, China; wanglimeiyx@163.com \\ 3 College of Biology and Pharmaceutical Engineering, Wuhan Polytechnic University, Wuhan 430023, China \\ * Correspondence: wanghongxun7736@163.com; Tel.: +86-27-8391-3403
}

Academic Editor: Derek J. McPhee

Received: 1 June 2016; Accepted: 27 June 2016; Published: 30 June 2016

\begin{abstract}
Lotus root attracts increasing attention mainly because of its phenolic compounds known as natural antioxidants. Its thirteen varieties were systematically analyzed on the content, distribution, composition and antioxidant activity of phenolic compounds for a better understanding of this aquatic vegetable. The respective mean contents of total phenolics in their flesh, peel and nodes were $1.81,4.30$ and $7.35 \mathrm{mg}$ gallic acid equivalents (GAE)/g fresh weight (FW), and those of total flavonoids were 3.35, 7.69 and $15.58 \mathrm{mg}$ rutin equivalents/g FW. The phenolic composition determined by a high-performance liquid chromatography method varied significantly among varieties and parts. The phenolics of flesh were mainly composed of gallocatechin and catechin; those of peel and node were mainly composed of gallocatechin, gallic acid, catechin and epicatechin. The antioxidant activities of phenolic extracts in increasing order were flesh, peel and node; their mean concentrations for 50\% inhibition of 2,2-diphenyl-1-picrylhydrazyl radical were 46.00, 26.43 and $21.72 \mu \mathrm{g} \mathrm{GAE} / \mathrm{mL}$, and their mean values representing ferric reducing antioxidant power were 75.91, 87.66 and $100.43 \mu \mathrm{g}$ Trolox equivalents/100 $\mu \mathrm{g}$ GAE, respectively. "Zoumayang", "Baheou", "No. 5 elian" and "Guixi Fuou" were the hierarchically clustered varieties with relatively higher phenolic content and stronger antioxidant activity as compared with the others. Especially, their nodes and peels are promising sources of antioxidants for human nutrition.
\end{abstract}

Keywords: lotus root; variety; phenolic compound; antioxidant activity

\section{Introduction}

Lotus (Nelumbo nucifera Gaertn.), a well-known aquatic plant of family Nelumbonaceae, has been widely cultivated for food production, ornamental horticulture and traditional Asian medicine in China, Korea, Japan and India [1,2]. Its root, which contains abundant dietary fibers, starches, sugars, proteins, amino acids, minerals, vitamins and phenolics [3-6], is popularly consumed as both a delicious and nutritional vegetable and a therapeutic herb [1,7]. Some pharmacological potentials of the ethanol- and methanol-soluble extracts of lotus root, including antioxidant [2], immunomodulatory [8], antiobesity [2,7], hypoglycemic [9], psychopharmacological [10] and memory-improving activities [11], are proposed to be closely related to phenolic compounds. To our knowledge, these compounds in lotus root have attracted increasing attention mostly for the substrate of enzymatic browning [12-14], but not the bioactive components for human nutrition.

Phenolic compounds are secondary metabolites involved in several plant growth and development processes. As natural antioxidants, they have been extensively studied in recent years for lowering the risk of diseases associated with oxidative stress $[15,16]$. Among more than 
thirty-six selected vegetables, lotus root exhibited the strongest antioxidant activities [6,17]. Phenolic compounds were regarded as the main contributors in consideration of the significant positive correlation between phenolics content and antioxidant capacity $[1,6,18]$. The content and composition of phenolic compounds have been well investigated in various lotus tissues [19-23], except the root. The structurally characterized phenolic compounds of lotus root include catechol, gallic acid, (+)-catechin, (-)-epicatechin, (+/-)-gallocatechin and chlorogenic acid [5,14,24,25], but their contents, distributions and antioxidant activities remain unclear.

For most plants, the content, composition, and antioxidant activity of phenolic compounds vary significantly among their varieties, such as Prunus persica L. Batsch [26] and Litchi chinensis Sonn [27]. However, little is known about the varieties of lotus root. Peel and nodes are the major by-products of fresh-cut lotus root, which is a minimally processed food with increasing attention [12,13]. Accordingly, peel and nodes are gradually being focused on for utilization. Their higher phenolics contents and stronger antioxidant activities compared with flesh imply better development prospects [6,25].

Considering the growing number of lotus root-derived extracts/foodstuffs and the increasing literature on their biological properties, the detailed characterization of the phenolic compounds from lotus root, with regards to the three parts from different varieties, should be investigated to obtain valuable evidence that supports future efforts toward the development and utilization of this aquatic vegetable. Therefore, the objectives of this work were: (1) to compare the content of total phenolics and total flavonoids (TPC and TFC) in the flesh, peel and node of thirteen lotus root varieties; (2) to investigate the varietal differences of phytochemicals and antioxidant activity and their potential correlations; and (3) to indicate the preponderant varieties for the development of natural phenolics.

\section{Results and Discussion}

\subsection{Contents of Total Phenolics and Total Flavonoids in the Different Parts of Lotus Root Varieties}

As seen in Table 1, both total phenolics contents (TPC) and total flavonoids contents (TFC) differed significantly among the three parts of lotus root $(p<0.05)$, and could be ordered as node $>$ peel $>$ flesh, as reported in previous studies $[1,6,25]$. TPC ranged from 1.10 to $2.58 \mathrm{mg}$ gallic acid equivalents/g fresh weight (mg GAE/g FW) among the fleshes, from 2.80 to $4.97 \mathrm{mg} \mathrm{GAE} / \mathrm{g}$ FW among the peels, and from 5.27 to $9.80 \mathrm{mg}$ GAE/g FW among the nodes. TFC ranged from 1.89 to $6.33 \mathrm{mg}$ rutin equivalents/g fresh weight (mg RE/g FW) among the fleshes, from 5.35 to $9.63 \mathrm{mg} \mathrm{RE} / \mathrm{g}$ FW among the peels, and from 12.46 to $16.72 \mathrm{RE} \mathrm{mg/g} \mathrm{FW} \mathrm{among} \mathrm{the} \mathrm{nodes.} \mathrm{Both} \mathrm{TPC} \mathrm{and} \mathrm{TFC} \mathrm{exhibited} \mathrm{high} \mathrm{coefficients} \mathrm{of}$ variation (CV) among the lotus root varieties, ranging from 14.01\% to 33.33\%. "Guixi Fuou", "Baheou", "No. 2 Wuzhi", "Changzhou Piaojiang" and "Baipaozi" showed relatively higher contents of phenolic compounds in comparison with the corresponding mean values. The mean value of TPC in the fleshes (1.81 mg GAE/g FW) was obviously higher than that measured by Yang (1.46 mg GAE/g FW) [6], which might be partly derived from the differences in genotype and extraction solvent. Methanol was more suited to the extraction of phenolics from lotus root than ethanol, acetone, ethyl acetate, dichloromethane, and petroleum ether [6]. The TPC of "No. 5 elian" flesh (1.39mg GAE/g FW) was close to the previous result using $80 \%$ ethanol solution as extraction solvent [6]. Phenolic compounds were widely investigated in both free and bound forms [28,29]. However, the bound phenolics of lotus root were ignored because of their low contents in all the parts. The highest contents of bound phenolics and bound flavonoids, both found in node, were $0.29 \mathrm{mg} \mathrm{GAE} / \mathrm{g}$ FW and $0.36 \mathrm{mg} \mathrm{RE} / \mathrm{g} \mathrm{FW}$, respectively [25].

\subsection{Contents of Individual Phenolic Compounds in the Different Part of Lotus Root Varieties}

On the basis of the previous investigations involved in the phenolic composition of lotus root [5,14,24,25] and other lotus tissues [19-23], the contents of Gallic acid, p-cumaric acid, gallocatechin, catechol, chlorogenic acid, (+)-catechin, caffeic acid,(-)-epicatechin and rutin were selectively determined by a high performance liquid chromatography (HPLC) method. Gallocatechin 
and catechin were the main phenolic compounds determined in lotus root flesh (Table 2), their mean contents were 893.57 and $18.92 \mu \mathrm{g} / \mathrm{g}$ FW, and their CVs of content among varieties were $25.39 \%$ and $23.36 \%$, respectively. Gallic acid and epicatechin were detected in some of the varieties with relatively low contents. The contents of Gallic acid were in the range of 7.01-12.18 $\mu \mathrm{g} / \mathrm{g}$ FW, and those of epicatechin were in the range of $10.87-18.73 \mu \mathrm{g} / \mathrm{g}$ FW. The results agreed with the previous works: the phenolic compounds of "Damaojie" flesh were mainly composed of gallic acid, D-(+)-catechin and L-(-)-epicatechin [14]; and those of "Piaohua" flesh juice were principally identified to be (+/-)-gallocatechin and (+)-catechin [24]. In addition, the flesh of "No. 2 Wuzhi" contained $8.69 \mu \mathrm{g} / \mathrm{g}$ FW of catechol, and that of "Baheou" contained $9.40 \mu \mathrm{g} / \mathrm{g}$ FW of quercetin.

Table 1. Contents of total phenolics and total flavonoids in the different parts of lotus root varieties.

\begin{tabular}{|c|c|c|c|c|c|c|}
\hline \multirow{2}{*}{ Varieties } & \multicolumn{3}{|c|}{ Total Phenolics Content (mg GAE/g FW) } & \multicolumn{3}{|c|}{ Total Flavonoids Content (mg RE/g FW) } \\
\hline & Flesh & Peel & Node & Flesh & Peel & Node \\
\hline No. 5 elian & $1.39 \pm 0.05^{b}$ & $4.97 \pm 0.04^{\mathrm{h}}$ & $6.09 \pm 0.06^{b}$ & $2.40 \pm 0.13^{b}$ & $9.26 \pm 0.00^{f}$ & $12.46 \pm 0.72^{\mathrm{a}}$ \\
\hline No. 7 elian & $1.81 \pm 0.04^{\mathrm{d}}$ & $3.96 \pm 0.11^{\mathrm{cd}}$ & $7.57 \pm 0.01^{\mathrm{d}}$ & $3.02 \pm 0.11^{\mathrm{cd}}$ & $7.03 \pm 0.00^{\mathrm{bc}}$ & $16.12 \pm 0.97^{\mathrm{d}}$ \\
\hline No. 8 elian & $1.10 \pm 0.06^{\mathrm{a}}$ & $3.69 \pm 0.16^{b}$ & $5.27 \pm 0.04^{\mathrm{a}}$ & $1.89 \pm 0.10^{\mathrm{a}}$ & $6.77 \pm 0.17^{\mathrm{b}}$ & $13.98 \pm 0.06^{\mathrm{b}}$ \\
\hline Yingcheng Bailian & $1.69 \pm 0.03^{c}$ & $3.89 \pm 0.06^{\mathrm{c}}$ & $6.95 \pm 0.19^{c}$ & $3.58 \pm 0.03^{\mathrm{e}}$ & $7.38 \pm 0.23$ cde & $14.30 \pm 0.95^{\mathrm{bc}}$ \\
\hline Zoumayang & $1.90 \pm 0.04$ de & $4.59 \pm 0.07^{\mathrm{e}}$ & $6.95 \pm 0.17^{c}$ & $3.30 \pm 0.17$ de & $7.55 \pm 0.20 \mathrm{e}$ & $14.33 \pm 0.10^{b c}$ \\
\hline Baipaozi & $1.82 \pm 0.05^{\mathrm{d}}$ & $4.68 \pm 0.10 \mathrm{fg}$ & $6.27 \pm 0.15^{b}$ & $3.32 \pm 0.13$ de & $9.25 \pm 0.21^{\mathrm{f}}$ & $15.82 \pm 0.20^{\mathrm{cd}}$ \\
\hline Bobaiou & $1.84 \pm 0.04^{\mathrm{d}}$ & $4.29 \pm 0.11^{\mathrm{e}}$ & $6.85 \pm 0.16^{c}$ & $3.06 \pm 0.14^{\mathrm{cd}}$ & $7.14 \pm 0.20 \mathrm{bcd}$ & $13.29 \pm 0.31^{a b}$ \\
\hline No. 2 Wuzhi & $1.96 \pm 0.09^{\text {ef }}$ & $4.92 \pm 0.17^{\mathrm{h}}$ & $9.80 \pm 0.25 \mathrm{~g}$ & $3.51 \pm 0.18^{\mathrm{e}}$ & $7.47 \pm 0.26 \mathrm{de}$ & $19.34 \pm 0.51^{\mathrm{e}}$ \\
\hline 8143 & $2.02 \pm 0.02^{\mathrm{f}}$ & $4.14 \pm 0.13^{\mathrm{de}}$ & $8.31 \pm 0.10^{\mathrm{e}}$ & $2.91 \pm 0.11^{\mathrm{c}}$ & $6.69 \pm 0.11 \mathrm{bc}$ & $16.11 \pm 0.87^{\mathrm{d}}$ \\
\hline $\begin{array}{l}\text { Changzhou } \\
\text { Piaojiangou }\end{array}$ & $1.66 \pm 0.01^{c}$ & $4.54 \pm 0.10^{\mathrm{f}}$ & $9.44 \pm 0.16^{\mathrm{f}}$ & $3.07 \pm 0.09 \mathrm{~cd}$ & $7.36 \pm 0.15^{\text {cde }}$ & $19.98 \pm 0.93^{e}$ \\
\hline
\end{tabular}

The statistical differences in individual content among varieties were evaluated with One-way analysis of variance and Student-Newman-Keuls test. Data marked with different letters are significantly different $(p<0.05)$, and marked with same letter are statistically indifferent $(p>0.05)$.

Table 2. Contents of individual phenolic compounds in the fleshes of lotus root varieties.

\begin{tabular}{ccccc}
\hline \multirow{2}{*}{ Varieties } & \multicolumn{4}{c}{ Content of Phenolic Compounds $(\mu \mathrm{g} / \mathrm{g}$ FW) } \\
\cline { 2 - 5 } & Gallic Acid & Gallocatechin & Catechin & Epicatechin \\
\hline No. 5 elian & - & $475.22 \pm 8.98$ & $13.51 \pm 0.38$ & $11.94 \pm 0.39$ \\
No. 6 elian & $12.18 \pm 1.10$ & $766.82 \pm 26.65$ & $18.56 \pm 0.65$ & $14.18 \pm 1.05$ \\
No. 7 elian & - & $536.42 \pm 30.99$ & $20.12 \pm 1.09$ & - \\
No. 8 elian & $9.80 \pm 1.52$ & $770.62 \pm 3.01$ & $11.07 \pm 0.22$ & $18.73 \pm 0.13$ \\
Yingcheng Bailian & - & $996.25 \pm 94.77$ & $24.49 \pm 4.33$ & - \\
Zoumayang & $7.01 \pm 0.35$ & $896.18 \pm 10.91$ & $19.71 \pm 0.18$ & $10.87 \pm 1.97$ \\
Guixi Fuou & - & $1184.79 \pm 21.33$ & $23.64 \pm 0.11$ & $11.26 \pm 0.23$ \\
Baheou & $8.82 \pm 0.70$ & $1150.82 \pm 12.95$ & $25.02 \pm 0.23$ & $11.94 \pm 0.39$ \\
Baipaozi & - & $1133.45 \pm 12.63$ & $17.98 \pm 0.41$ & $12.03 \pm 0.74$ \\
Bobaiou & - & $856.09 \pm 9.93$ & $13.09 \pm 0.37$ & $14.30 \pm 0.76$ \\
No. 2 Wuzhi & - & $923.70 \pm 43.71$ & $22.01 \pm 0.77$ & - \\
8143 & - & $1125.76 \pm 42.30$ & $20.08 \pm 0.94$ & - \\
Changzhou & - & $800.25 \pm 5.66$ & $16.67 \pm 0.68$ & - \\
Piaojiangou & - & & & - \\
\hline
\end{tabular}

- means the compound has not been detected.

The phenolic composition of peel, mainly including gallic acid, gallocatechin, catechol, catechin, caffeic acid, epicatechin and rutin, was obviously different from that of flesh, and also showed obvious differences among the varieties, as shown in Table 3. Gallic acid, gallocatechin, catechol and catechin were detected in the peels of all thirteen varieties, their mean contents were 23.80, 761.59, 6.04 and $22.66 \mu \mathrm{g} / \mathrm{g} \mathrm{FW}$, and their CVs of content among varieties were $71.32 \%, 50.05 \%, 20.81 \%$ and $26.09 \%$, respectively. Among which, gallic acid was confirmed to be the primary substrate 
participating in the browning of lotus root [30]. Caffeic acid, epicatechin and rutin were detected in most of the peels individually in the content range of 1.52-32.46 $\mu \mathrm{g} / \mathrm{g}$ FW, 29.89-151.52 $\mu \mathrm{g} / \mathrm{g}$ FW and 15.57-46.69 $\mu \mathrm{g} / \mathrm{g}$ FW, respectively. In addition, $p$-cumaric acid, chlorogenic acid and quercetin were not detected in peel for more than half of the varieties. Uniquely, the peel of "Baipaozi" contained $34.14 \mu \mathrm{g} / \mathrm{g}$ FW of $p$-cumaric acid.

The phenolic composition of node was almost the same as that of peel (Table 4). Gallic acid (mean content $26.76 \mu \mathrm{g} / \mathrm{g} \mathrm{FW}, \mathrm{CV} 47.99 \%$ ), gallocatechin (mean content $840.44 \mu \mathrm{g} / \mathrm{g}$ FW, CV 40.65\%), catechol (mean content 7.87 $\mu \mathrm{g} / \mathrm{g}$ FW, CV 18.75\%), catechin (mean content $31.82 \mu \mathrm{g} / \mathrm{g} \mathrm{FW,} \mathrm{CV} \mathrm{45.58 \% )} \mathrm{and}$ epicatechin (mean content $37.50 \mu \mathrm{g} / \mathrm{g} \mathrm{FW}, \mathrm{CV} 53.76 \%$ ) were all detected in the tested nodes. Both the mean contents of gallocatechin and catechin in node were obviously higher than those in peel. The information on the phenolic composition of node was rare. Li et al. found that the hydrolysable tannins isolated from "Damaojie" node were mainly composed of gallic acid and ellagic acid [31]. Moreover, other phenolic compounds mentioned in the previous work, such asleucocyanidin and leucodephinidin [4], were not found in all the parts of lotus root. To sum up, lotus root exhibited the germplasm diversity in phenolic distribution and composition, and the diversity might be useful for resource identification and evaluation.

\subsection{Antioxidant Activities of Phenolic Compounds from the Different Parts of Lotus Root Varieties}

Oxidative stress, defined as the imbalance between free radical production and antioxidant defenses, is a condition associated with many chronic-degenerative diseases. Effects of fruits, vegetables and their antioxidants on the improvement of antioxidant levels in vivo have attracted much attention, and the resulting antioxidant activities are attributed to various mechanisms [32]. Herein, 2,2-diphenyl-1-picrylhydrazyl (DPPH) radical scavenging capacity assay and reducing antioxidant power (FRAP) assay were selected to evaluate the antioxidant activities of phenolics extracts from lotus root, as shown in Table 5. The mean concentrations for 50\% inhibition $\left(\mathrm{IC}_{50}\right)$ of $\mathrm{DPPH}$ radical of flesh, peel and node were 46.00, 26.43 and $21.72 \mu \mathrm{g}$ GAE/mL, and those of FRAP antioxidant activity were $62.18,82.05$ and $95.14 \mu \mathrm{g}$ TE/100 $\mu \mathrm{g}$ GAE, respectively. The antioxidant ability of lotus root could be characterized as node $>$ peel $>$ flesh, which was consistent with the previous investigations $[1,6,25]$. Among the thirteen varieties, the $\mathrm{IC}_{50}$ values of $\mathrm{DPPH}$ radical scavenging showed significant differences with the CV of $14.03 \%, 30.42 \%$ and $11.81 \%$, respectively. The values of FRAP for peel and node, by contrast, exhibited minor differences $(\mathrm{CV}<10 \%)$. The antioxidant activities of lotus root and its extracts showed significant correlations with TPC [1,6,33], and this correlation was widely confirmed in similar investigations on other plant materials, such as mulberry leaves [34], apples [35] and brown rice [29,36]. To explore the main components contributing to the antioxidant activity of lotus root, the Pearson's correlation between individual phenolic contents and antioxidant activities was analyzed. According to the correlation coefficients summarized in Table 6, the two antioxidant activities had a negative correlation $(p<0.001)$; DPPH radical scavenging activity showed significant correlations with both the contents of catechin and epicatechin $(p<0.05)$; and FRAP antioxidant activity exhibited a positive correlation with catechin content $(p<0.001)$. Lachman et al. deemed that the antioxidant activity of potato flesh was synthetically provided by chlorogenic acid, gallic acid, caffeic acid and catechin [37]. The co-existence of different phenolic compounds might result in the synergistic action of antioxidant activity, which might be related to their structures [28]. Compounds with catechol moieties, multiple hydroxyl groups, and conjugation with electron-donating groups at the 4-location of the aromatic ring positively impacted the antioxidant activity [28]. It was implied that the main contributors to the antioxidant activity of lotus root might be catechin and epicatechin, but the potential synergistic effect and the relationship between structure and activity were unavailable. 
Table 3. Contents of individual phenolic compounds in the peels of lotus root varieties.

\begin{tabular}{|c|c|c|c|c|c|c|c|c|c|c|}
\hline \multirow[b]{2}{*}{ Varieties } & \multicolumn{10}{|c|}{ Content of Phenolic Compounds ( $\mu \mathrm{g} / \mathrm{g}$ FW) } \\
\hline & Gallic Acid & $p$-Cumaric Acid & Gallocatechin & Catechol & Chlorogenic Acid & Catechin & Caffeic Acid & Epicatechin & Rutin & Quercetin \\
\hline No. 5 elian & $29.67 \pm 2.61$ & $13.79 \pm 1.85$ & $282.45 \pm 16.53$ & $7.09 \pm 0.46$ & - & $21.55 \pm 1.37$ & $5.91 \pm 0.36$ & $131.17 \pm 9.51$ & $34.46 \pm 1.91$ & - \\
\hline No. 6 elian & $53.72 \pm 8.64$ & - & $280.74 \pm 3.67$ & $4.10 \pm 0.03$ & - & $12.48 \pm 0.34$ & $6.75 \pm 0.30$ & $151.52 \pm 15.35$ & $15.57 \pm 1.32$ & - \\
\hline No. 7 elian & $51.14 \pm 1.32$ & - & $379.02 \pm 17.22$ & $5.36 \pm 0.25$ & - & $22.61 \pm 2.01$ & $6.10 \pm 1.09$ & $49.68 \pm 4.11$ & $23.52 \pm 2.34$ & - \\
\hline No. 8 elian & $37.97 \pm 3.89$ & 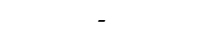 & $494.63 \pm 5.52$ & $5.30 \pm 0.07$ & - & $20.98 \pm 0.18$ & $2.96 \pm 0.27$ & $61.41 \pm 3.81$ & $46.69 \pm 3.79$ & $146.77 \pm 11.09$ \\
\hline Yingcheng Bailian & $23.25 \pm 1.84$ & - & $742.34 \pm 68.92$ & $6.42 \pm 0.11$ & 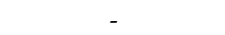 & $27.87 \pm 1.49$ & & $29.89 \pm 1.06$ & $26.14 \pm 1.81$ & $9.70 \pm 0.39$ \\
\hline Zoumayang & $26.60 \pm 3.44$ & $86.51 \pm 3.08$ & $1113.40 \pm 123.55$ & $4.20 \pm 0.37$ & $40.59 \pm 3.99$ & $16.08 \pm 0.61$ & $5.65 \pm 0.37$ & $106.84 \pm 6.01$ & $18.56 \pm 1.43$ & -1.00 \\
\hline Guixi Fuou & $4.36 \pm 0.60$ & & $1583.30 \pm 128.74$ & $8.16 \pm 1.26$ & & $30.87 \pm 3.31$ & $2.86 \pm 0.26$ & $65.20 \pm 3.28$ & $22.03 \pm 0.79$ & - \\
\hline Baheou & $24.49 \pm 1.69$ & $42.50 \pm 2.46$ & $975.24 \pm 119.89$ & $6.76 \pm 0.32$ & $46.26 \pm 4.82$ & $12.72 \pm 0.75$ & $3.90 \pm 0.12$ & $63.60 \pm 0.81$ & $24.52 \pm 2.30$ & $10.62 \pm 0.16$ \\
\hline Baipaozi & $5.37 \pm 0.09$ & & $1088.20 \pm 339.46$ & $7.28 \pm 0.92$ & $36.27 \pm 0.30$ & $22.46 \pm 3.72$ & $4.75 \pm 0.49$ & $109.88 \pm 9.67$ & $23.15 \pm 3.17$ & \\
\hline Bobaiou & $5.12 \pm 0.25$ & $47.32 \pm 0.11$ & $747.94 \pm 51.31$ & $5.12 \pm 0.05$ & & $28.69 \pm 1.51$ & $3.70 \pm 0.11$ & $66.50 \pm 2.52$ & & $9.94 \pm 0.10$ \\
\hline No. 2 Wuzhi & $13.13 \pm 1.54$ & - & $747.00 \pm 21.21$ & $6.66 \pm 0.46$ & - & $26.62 \pm 0.99$ & $32.46 \pm 0.86$ & & $31.65 \pm 1.74$ & - \\
\hline 8143 & $29.74 \pm 2.43$ & & $969.20 \pm 111.19$ & $5.61 \pm 0.17$ & - & $23.51 \pm 2.46$ & $1.52 \pm 0.05$ & $38.56 \pm 3.13$ & & - \\
\hline Changzhou Piaojiangou & $4.91 \pm 0.19$ & $11.21 \pm 0.70$ & $496.93 \pm 21.28$ & $7.52 \pm 0.26$ & - & $27.06 \pm 1.04$ & $2.63 \pm 0.08$ & $88.96 \pm 1.15$ & $23.73 \pm 0.87$ & - \\
\hline
\end{tabular}

Table 4. Contents of individual phenolic compounds in the nodes of lotus root varieties.

\begin{tabular}{|c|c|c|c|c|c|c|c|c|c|c|}
\hline \multirow{2}{*}{ Varieties } & \multicolumn{10}{|c|}{ Content of Phenolic Compounds ( $\mu \mathrm{g} / \mathrm{g}$ FW) } \\
\hline & Gallic Acid & $p$-Cumaric Acid & Gallocatechin & Catechol & Chlorogenic Acid & Catechin & Caffeic Acid & Epicatechin & Rutin & Quercetin \\
\hline No. 5 elian & $23.07 \pm 2.26$ & $14.55 \pm 1.65$ & $424.64 \pm 15.80$ & $6.51 \pm 0.57$ & - & $37.78 \pm 2.99$ & $1.91 \pm 0.20$ & $34.40 \pm 0.66$ & & - \\
\hline No. 6 elian & $37.98 \pm 1.27$ & $12.04 \pm 0.16$ & $527.43 \pm 2.50$ & $7.50 \pm 0.15$ & - & $37.55 \pm 5.36$ & $2.87 \pm 0.51$ & $40.14 \pm 0.83$ & $10.43 \pm 0.50$ & - \\
\hline No. 7 elian & $34.10 \pm 2.82$ & - & $436.25 \pm 26.90$ & $6.82 \pm 0.88$ & - & $25.63 \pm 2.38$ & $7.66 \pm 1.10$ & $18.52 \pm 1.45$ & & - \\
\hline No. 8 elian & $28.86 \pm 3.69$ & - & $612.35 \pm 53.73$ & $8.25 \pm 0.54$ & - & $33.89 \pm 1.07$ & 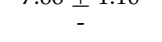 & $18.26 \pm 2.00$ & $18.05 \pm 2.16$ & - \\
\hline Yingcheng Bailian & $19.72 \pm 0.30$ & $72.72 \pm 3.10$ & $1112.38 \pm 23.80$ & $\begin{array}{r}10.36 \pm \\
0.08\end{array}$ & - & $61.15 \pm 1.22$ & - & $14.69 \pm 1.79$ & $25.41 \pm 1.25$ & - \\
\hline Zoumayang & $38.36 \pm 2.55$ & - & $979.08 \pm 18.18$ & $\begin{array}{c}0.40 \pm 0.49 \\
6.40\end{array}$ & $47.67 \pm 0.66$ & $13.84 \pm 0.99$ & $1.90 \pm 0.18$ & $29.22 \pm 3.51$ & $19.60 \pm 2.17$ & ـ \\
\hline Guixi Fuou & $48.27 \pm 3.94$ & & $1257.40 \pm 30.15$ & $9.33 \pm 0.47$ & & $12.17 \pm 0.60$ & $4.28 \pm 0.48$ & $82.89 \pm 3.29$ & $29.36 \pm 1.35$ & $9.22 \pm 0.16$ \\
\hline Baheou & $15.50 \pm 0.74$ & $32.54 \pm 2.95$ & $883.07 \pm 23.84$ & $7.72 \pm 0.59$ & $55.34 \pm 5.36$ & $42.32 \pm 4.19$ & $1.96 \pm 0.01$ & $18.99+0.30$ & - & $9.54+0.04$ \\
\hline Baipaozi & $30.28 \pm 2.26$ & & $1411.69 \pm 164.69$ & $6.22 \pm 0.54$ & & $15.18 \pm 2.40$ & $3.81 \pm 1.39$ & $38.10 \pm 2.69$ & - & $11.44 \pm 1.11$ \\
\hline Bobaiou & $5.26 \pm 2.35$ & $36.02 \pm 2.50$ & $340.32 \pm 29.30$ & $8.38 \pm 0.86$ & - & $35.60 \pm 3.84$ & $5.24 \pm 0.47$ & $48.88 \pm 1.14$ & - & $10.26 \pm 0.21$ \\
\hline No. 2 Wuzhi & $39.65 \pm 6.05$ & $50.02 \pm 2.00$ & $1028.34 \pm 45.42$ & $\begin{array}{l}0.00 \pm 0.00 \\
5.89 \pm 0.19\end{array}$ & $45.30 \pm 1.06$ & $15.74 \pm 1.99$ & $6.44 \pm 0.35$ & $43.91 \pm 0.85$ & $28.56 \pm 1.93$ & $10.20 \pm 0.21$ \\
\hline 8143 & $15.66 \pm 2.82$ & $47.76 \pm 4.70$ & $897.09 \pm 36.42$ & $9.15 \pm 0.70$ & $43.00 \pm 1.00$ & $41.56 \pm 2.86$ & $3.75 \pm 0.54$ & $31.46 \pm 2.78$ & $22.00 \pm 0.77$ & $22.90 \pm 4.18$ \\
\hline Changzhou Piaojiangou & $11.16 \pm 2.65$ & $64.51 \pm 3.94$ & $1015.70 \pm 39.24$ & $9.84 \pm 0.76$ & - & $41.20 \pm 2.73$ & $5.24 \pm 0.52$ & $68.01 \pm 7.70$ & & $22.70 \perp+.10$ \\
\hline
\end{tabular}


Table 5. Antioxidant activities of phenolic compounds from the different parts of lotus root varieties.

\begin{tabular}{|c|c|c|c|c|c|c|}
\hline \multirow{2}{*}{ Varieties } & \multicolumn{3}{|c|}{$\mathrm{IC}_{50}$ of DPPH Radical Scavenging ( $\mu \mathrm{g}$ GAE $/ \mathrm{mL}$ ) } & \multicolumn{3}{|c|}{ FRAP Antioxidant Activity ( $\mu$ g TE/100 $\mu$ g GAE) } \\
\hline & Flesh & Peel & Node & Flesh & Peel & Node \\
\hline No. 5 elian & $37.44 \pm 1.52^{\mathrm{a}}$ & $22.37 \pm 1.06^{\mathrm{ab}}$ & $19.04 \pm 0.37^{\mathrm{a}}$ & $79.92 \pm 7.31^{b c}$ & $92.59 \pm 3.78^{b}$ & $110.08 \pm 3.69^{\mathrm{cd}}$ \\
\hline No. 6 elian & $59.39 \pm 1.25^{\mathrm{e}}$ & $24.80 \pm 2.71^{\mathrm{ab}}$ & $18.98 \pm 1.38^{\mathrm{a}}$ & $75.23 \pm 2.64^{b}$ & $82.88 \pm 2.72^{a b}$ & $105.70 \pm 5.81 \mathrm{bcd}$ \\
\hline No. 7 elian & $49.99 \pm 0.74^{\mathrm{c}}$ & $24.11 \pm 0.94 \mathrm{ab}$ & $24.07 \pm 0.85^{b}$ & $86.16 \pm 1.44 \mathrm{~cd}$ & $84.64 \pm 3.84 \mathrm{ab}$ & $106.97 \pm 2.80^{\mathrm{bcd}}$ \\
\hline No. 8 elian & $43.36 \pm 1.21^{b}$ & $23.78 \pm 3.08^{a b}$ & $21.05 \pm 0.02 \mathrm{a}$ & $63.13 \pm 1.62^{\mathrm{a}}$ & $94.15 \pm 3.45^{b}$ & $107.20 \pm 7.31 \mathrm{bcd}$ \\
\hline Yingcheng Bailian & $55.04 \pm 3.96^{\mathrm{d}}$ & $51.50 \pm 2.05^{\mathrm{d}}$ & $21.14 \pm 1.83^{a}$ & $77.71 \pm 2.88^{b}$ & $92.17 \pm 2.87^{b}$ & $107.29 \pm 10.46^{\mathrm{bcc}}$ \\
\hline Zoumayang & $43.46 \pm 2.58^{b}$ & $22.95 \pm 1.38^{\mathrm{ab}}$ & $18.74 \pm 0.41^{\mathrm{a}}$ & $94.38 \pm 1.92^{\mathrm{e}}$ & $98.15 \pm 9.50^{b}$ & $98.74 \pm 2.99 \mathrm{bcd}$ \\
\hline Guixi Fuou & $42.73 \pm 3.49^{b}$ & $19.94 \pm 0.83^{\mathrm{a}}$ & $19.96 \pm 0.65^{\mathrm{a}}$ & $74.10 \pm 5.81^{\mathrm{b}}$ & $94.32 \pm 5.10^{b}$ & $112.32 \pm 2.11^{\mathrm{d}}$ \\
\hline Baheou & $37.52 \pm 3.13^{a}$ & $20.23 \pm 1.29^{a}$ & $19.66 \pm 0.18^{a}$ & $91.00 \pm 4.32$ de & $93.28 \pm 6.73^{b}$ & $100.59 \pm 9.96^{b c d}$ \\
\hline Baipaozi & $49.55 \pm 1.45^{c}$ & $25.28 \pm 3.62^{a b}$ & $24.90 \pm 1.64^{b}$ & $76.12 \pm 5.31^{b}$ & $87.35 \pm 2.25^{\mathrm{ab}}$ & $78.78 \pm 2.38^{a}$ \\
\hline Bobaiou & $43.06 \pm 0.91^{b}$ & $24.61 \pm 2.67^{\mathrm{ab}}$ & $20.42 \pm 0.84^{a}$ & $65.38 \pm 6.05^{\mathrm{a}}$ & $82.41 \pm 4.17^{\mathrm{ab}}$ & $92.76 \pm 8.37^{b}$ \\
\hline No. 2 Wuzhi & $42.67 \pm 1.94^{b}$ & $25.86 \pm 1.19^{b}$ & $24.23 \pm 0.70^{b}$ & $75.65 \pm 1.82^{b}$ & $82.20 \pm 4.85^{\mathrm{ab}}$ & $97.19 \pm 1.93 \mathrm{bcd}$ \\
\hline 8143 & $50.03 \pm 2.01^{c}$ & $30.45 \pm 1.53^{c}$ & $24.54 \pm 0.26^{b}$ & $65.83 \pm 3.06^{\mathrm{a}}$ & $73.33 \pm 5.86^{\mathrm{a}}$ & $92.82 \pm 3.01^{b}$ \\
\hline Changzhou Piaojiangou & $43.75 \pm 2.79^{b}$ & $27.70 \pm 1.39 \mathrm{bc}$ & $25.68 \pm 1.34^{b}$ & $62.18 \pm 2.34^{a}$ & $82.05 \pm 7.47^{a b}$ & $95.14 \pm 4.61 \mathrm{bc}$ \\
\hline Mean & 46.00 & 26.43 & 21.72 & 75.91 & 87.66 & 100.43 \\
\hline Coefficient of variation & $14.03 \%$ & $30.42 \%$ & $11.81 \%$ & $13.51 \%$ & $8.06 \%$ & $9.20 \%$ \\
\hline
\end{tabular}

The statistical difference in individual activity among varieties was evaluated with One-way analysis of variance and Student-Newman-Keuls test. Data marked with different letters are significantly different $(p<0.05)$, and marked with same letter are statistically indifferent $(p>0.05)$

Table 6. Pearson's correlation between phenolic contents and antioxidant activities.

\begin{tabular}{ccc}
\hline Variates & \multicolumn{2}{c}{ Coefficient of Correlation } \\
\cline { 2 - 3 } & IC $_{50}$ of DPPH Radical Scavenging & FRAP Antioxidant Activity \\
\hline IC $_{50}$ of DPPH radical scavenging $(n=39)$ & & $-0.672 * *$ \\
FRAP antioxidant activity $(n=39)$ & $-0.672^{* *}$ & 0.274 \\
Gallic acid content $(n=30)$ & -0.308 & -0.088 \\
Gallocatechin content $(n=39)$ & 0.104 & 0.358 \\
Catechol content $(n=27)$ & -0.066 & $0.473^{* *}$ \\
Catechin content $(n=39)$ & $-0.332^{*}$ & 0.103 \\
Epicatechin content $(n=34)$ & $-0.433^{*}$ & \\
\hline
\end{tabular}

$* *$ means the significance level of $p<0.001$, and * means the significance level of $p<0.05$ 
A hierarchical cluster analysis, based on Ward's linkage and squared Euclidean distance using the " $0-1$ "standardized values of TPC, TFC, DPPH radical scavenging $\left(\mathrm{IC}_{50}\right)$ and FRAP antioxidant activity, was conducted to measure the similarity among lotus root varieties, as seen in Figure 1 . The varieties fell into three classes at distance 10, in which Class-I included "No. 2 Wuzhi", "Changzhou Piaojiangou", "Bobaiou", “8143" and "Baipaozi"; Class-II included "No. 7 elian”, "Yingcheng Bailian”, "No. 6 elian" and "No. 8 elian"; and Class-III included "Zoumayang", "Baheou", "No. 5 elian" and "Guixi Fuou". The difference of phenolic compounds among the classes was explored (Table 7). The TPC values of flesh and node both showed no significant difference among the classes $(p>0.05)$, as well as the TFC values. Class-I and Class-III exhibited no significant difference in the TPC and TFC of peel $(p>0.05)$, and both had higher content values compared with Class-II. The antioxidant difference between Class-I and Class-II was statistically insignificant $(p>0.05)$, except that in the FRAP antioxidant activity of node $(p<0.05)$. Class-III had stronger activities than Class-I involving in the FRAP antioxidant activity of all three parts and the DPPH radical scavenging activity of node $(p<0.05)$. The activities of Class-II were comparable to those of Class-III, except the DPPH radical scavenging activity of flesh $(p<0.05)$. It was suggested that Class-III were better for developing novel value-added antioxidant products. However, none of the varieties in Class-III have been deeply investigated on the antioxidant effect of phenolic compounds.

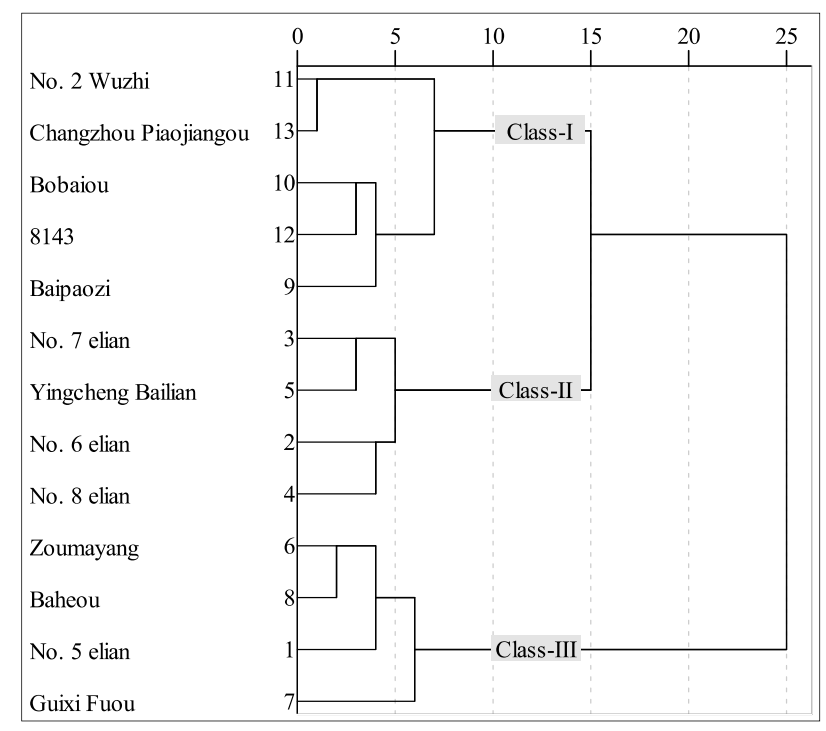

Figure 1. Hierarchical cluster diagram of lotus root varieties based on the content and antioxidant activity of phenolic compounds.

Table 7. Phenolic contents and antioxidant activities of three classes of lotus root.

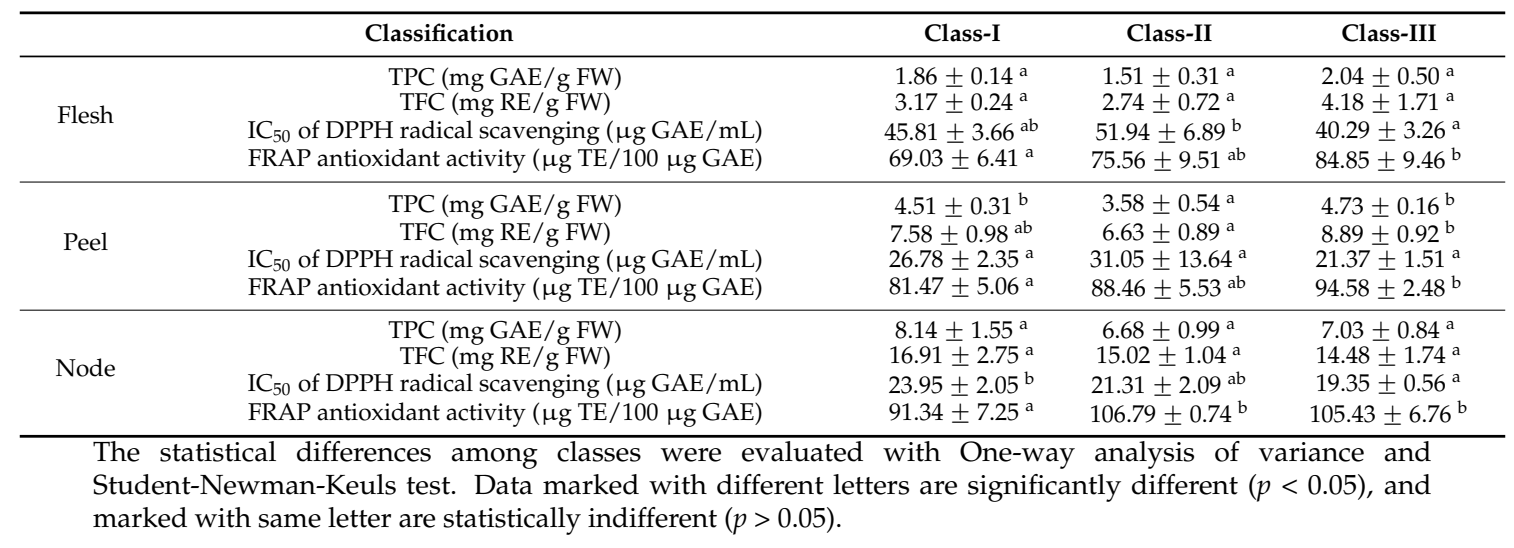




\section{Materials and Methods}

\subsection{Plant Material and Chemicals}

Thirteen commercially cultivated varieties of lotus root, namely "No. 5 elian", "No. 6 elian", "No. 7 elian", "No. 8 elian”, "Yingcheng Bailian", "Zoumayang”, "Guixi Fuou”, "Baheou”, "Baipaozi”, "Bobaiou", "No. 2 Wuzhi", "8143" and "Changzhou Piaojiangou”, were provided by National Aquatic Vegetable Germplasm Repository (Wuhan, China) and identified by professor Yi-man Liu and senior agronomist Jing Peng (Wuhan Vegetable Research Institute, Wuhan, China). The fresh materials were harvested in October 2015. After cleaning well and cooling to $4{ }^{\circ} \mathrm{C}$, lotus roots were manually cut into three parts, flesh, peel (about $0.1 \mathrm{~cm}$ thick) and node, followed by grinding individually in a food processor (HR7629/00, Philips Corporation, Huizhou, China). The prepared materials were then stored at $-20{ }^{\circ} \mathrm{C}$.

DPPH, TPTZ (2,4,6-tripyridyl-Striazine), Trolox (6-hydroxy-2,5,7,8-tetramethylchroman-2-carboxylic acid), gallic acid and rutin were purchased from Tokyo Chemical Industry Co., Ltd (Shanghai, China). Folin-Ciocalteu, (+)-catechin, (-)-epicatechin, resveratrol, $p$-cumaric acid, caffeic acid, quercetin and chlorogenic acid were purchased from Sigma-Aldrich Co., LLC (St. Louis, MO, USA). HPLC-grade acetonitrile and acetic acid were purchased from Fisher Scientific Co. (Pittsburgh, PA, USA). Other chemicals were analytical grade and purchased from Sinopharm Chemical Reagent Co., Ltd. (Shanghai, China).

\subsection{Extraction of Phenolic Compounds}

The phenolic compounds were extracted from different parts of lotus root according to previous methods [25,29] with minor modifications. Flesh, peel or node samples $(5.0 \mathrm{~g})$, soaked in $50 \mathrm{~mL}$ of $4{ }^{\circ} \mathrm{C}$ pre-cooled $80 \%$ methanol acidified with $2 \%$ formic acid, were homogenized at 10,500 r/min for $4 \mathrm{~min}$ using a XHF-D high-shear homogenizer (Ningbo xinzhi biotechnology Co., Ltd, Ningbo, China). The homogenate was centrifuged at 10,000 r/min for $5 \mathrm{~min}$, followed by filtration through a Whatman No. 1 filter paper, to separate supernatant. The residues were homogenized with $50 \mathrm{~mL}$ solvent again to collect supernatant. The supernatants were combined and concentrated at $50{ }^{\circ} \mathrm{C}$ using a vacuum rotary evaporator (BC-R203, Shanghai Biochemical Equipment Co., Shanghai, China), and diluted with methanol to $25 \mathrm{~mL}$. The extract was then filtered through a $0.45-\mu \mathrm{m}$ syringe filter prior to subsequent analysis. The preparation was performed in triplicate for each sample.

\subsection{Determination of Total Phenolics and Total Flavonoids}

TPC was measured according to the Folin-Ciocalteu method [38] with minor modifications. The phenolic extract $(0.125 \mathrm{~mL})$, Folin-Ciocalteu reagent $(0.125 \mathrm{~mL})$ and distilled water $(0.5 \mathrm{~mL})$ were mixed in a centrifuge tube. After incubation for $6 \mathrm{~min}, 2.25 \mathrm{~mL}$ of $3.5 \% \mathrm{Na}_{2} \mathrm{CO}_{3}$ solution $(\mathrm{m} / \mathrm{v})$ was added. The mixture was then kept in dark at room temperature for $90 \mathrm{~min}$, followed by absorbance determination at $760 \mathrm{~nm}$ using a UV-visible spectrophotometer (Shimadzu, UV-1800, Kyoto, Japan). Meanwhile, gallic acid $(50-500 \mu \mathrm{g} / \mathrm{mL})$ was used as standard to establish a calibration curve. TPC (mg GAE/g FW) was measured in triplicate.

TFC was measured according to the method described by Jia et al. [39], with minor modifications. Briefly, $0.3 \mathrm{~mL}$ phenolic extract was sequentially mixed with $1.5 \mathrm{~mL}$ methanol, $0.09 \mathrm{~mL}$ of $5 \% \mathrm{NaNO}_{2}$ solution $(\mathrm{m} / \mathrm{v})$, and $0.18 \mathrm{~mL}$ of $10 \% \mathrm{AlCl}_{3} \cdot 6 \mathrm{H}_{2} \mathrm{O}$ solution $(\mathrm{m} / \mathrm{v})$. After incubation for $5 \mathrm{~min}, 0.6 \mathrm{~mL}$ of $1 \mathrm{~mol} / \mathrm{L} \mathrm{NaOH}$ solution and $0.33 \mathrm{~mL}$ distilled water were added to the mixture. The absorbance of the mixture was read at $510 \mathrm{~nm}$. Meanwhile, rutin (20-100 $\mathrm{gg} / \mathrm{mL})$ was used as standard to establish a calibration curve. TFC (mg RE/g FW) was measured in triplicate.

\subsection{Chromatographic Analysis of Phenolic Compounds}

HPLC analysis was conducted on a Waters series system equipped with a 2487 ultraviolet-visible detector, a 1525 binary pump (Waters, Milford, MA, USA) and a Luna C18(2) column 
$\left(250 \mathrm{~mm} \times 4.6 \mathrm{~mm}\right.$, Phenomenex, Torrance, CA, USA) maintained at $30{ }^{\circ} \mathrm{C}$. The flow rate was $1.0 \mathrm{~mL} / \mathrm{min}$, the injection volume was $20 \mu \mathrm{L}$, and the absorbance was detected at $280 \mathrm{~nm}$. The mobile phases consisted of (A) acetonitrile and (B) $0.4 \%$ acetic acid ( $v / v)$. An elution gradient was implemented as follows: 5\% (A) and 95\% (B) to 25\% (A) and 75\% (B) over $30 \mathrm{~min}$; to 50\% (A) and $50 \%$ (B) over $10 \mathrm{~min}$; to 5\% (A) and 95\% (B) over $15 \mathrm{~min}$; and re-equilibration over $10 \mathrm{~min}$. External standard method and internal standard method were simultaneously used for the identification of chromatographic peaks with authentic standards. Each sample was performed in triplicate. The calibration curve of each standard, based on serial concentrations and their corresponding peak areas, was used for quantitation.

\subsection{Evaluation of Antioxidant Activities}

DPPH radical scavenging activity was evaluated by the method of Brand-Williams et al. [40], with slight modifications. Briefly, $50 \mu \mathrm{L}$ sample solution with an appropriate phenolic concentration adjusted by methanol was mixed with $0.7 \mathrm{~mL}$ of a $0.1 \mathrm{~mol} / \mathrm{mL}$ methanolic solution of DPPH. After incubation under darkness at room temperature for $30 \mathrm{~min}$, the absorbance of the mixture was measured at $517 \mathrm{~nm}$. All determinations were performed in triplicate. The scavenging percent $(\mathrm{S}, \%)$ of DPPH radicals was calculated using the equation:

$$
S(\%)=\left(\left(A_{c}-A_{S}\right) / A_{c}\right) \times 100
$$

where $A_{c}$ is the absorbance of the control, and $A_{s}$ is the absorbance of the sample. $\mathrm{IC}_{50}$ value was calculated as the phenolic concentration $(\mu \mathrm{g}$ GAE $/ \mathrm{mL}$ ) with $50 \%$ scavenging of DPPH radicals.

Total antioxidant power was determined using the FRAP assay [41], with slight modifications. The FRAP reagent was prepared by mixing $300 \mathrm{mmol} / \mathrm{L}$ acetate buffer (pH 3.6), $10 \mathrm{mmol} / \mathrm{L} \mathrm{TPTZ}$ solution in $40 \mathrm{mmol} / \mathrm{L} \mathrm{HCl}$ and $20 \mathrm{mmol} / \mathrm{L} \mathrm{FeCl}_{3}$ solution at a volume ratio of 10:1:1, and preheated to $37^{\circ} \mathrm{C}$ for use. Sample solution $(1 \mathrm{~mL})$ with an appropriate phenolic concentration adjusted by methanol was mixed with $1.8 \mathrm{~mL}$ FRAP reagent. After incubation under darkness at room temperature for $10 \mathrm{~min}$, the absorbance of the mixture was measured at $593 \mathrm{~nm}$. All determinations were performed in triplicate. Different concentrations of Trolox were determined for a standard curve. The FRAP antioxidant activity of sample solution was corrected with total phenolics concentration and expressed as $\mu \mathrm{g}$ TE/100 $\mu \mathrm{g}$ GAE.

\subsection{Statistical Analysis}

IBM SPSS Statistics 19 software (IBM, Armonk, NY, USA) was used for statistical analysis. The data were expressed as means \pm standard deviations from triplicate experiments. The significance of difference at a level of 0.05 was evaluated with ANOVA (One-way analysis of variance) and SNK (Student-Newman-Keuls) test. Pearson's correlation test was used to identify correlation between groups. Hierarchical cluster analysis was conducted with Ward's method of linkage and squared Euclidean distance as a measure of the similarity among varieties.

\section{Conclusions}

Thirteen extensively cultivated varieties of lotus root were investigated on phenolic profiles and antioxidant activity for a better understanding on the high-value utilization of this aquatic vegetable in functional food industry. The varieties showed significant differences in the content, distribution, composition and antioxidant activity of phenolic compounds. "Zoumayang", "Baheou”, "No. 5 elian" and "Guixi Fuou" possessed relatively higher phenolic content and stronger antioxidant activity compared with others. As the main by-products of lotus root, node and peel exhibited higher phenolics content, stronger antioxidant activity and more phenolic compounds than the edible flesh. The differences among the varieties and parts should be considered for consumption and nutraceutical purposes. Catechin and epicatechin were suggested to be the primary contributors to the antioxidant 
activity of lotus root, but the potential synergies cooperated with other phenolic compounds should be further explored. Therefore, the fingerprint of phenolic compounds of lotus root needs to be further analyzed in detail.

Acknowledgments: We gratefully acknowledge the financial support by Key Technology R\&D Program of Hubei Province (2015BBA203) and Youth Chenguang Program of Science and Technology in Wuhan (Database Establishment of Bioactive Components for Germplasm Resources of Lotus Root, 2016).

Author Contributions: Y.Y. and H.W. conceived and designed the experiments; Y.Y., J.S., J.X. and T.M. performed the experiments; Y.Y. and L.W. analyzed the data; and Y.Y. and H.W. wrote the paper.

Conflicts of Interest: The authors declare no conflict of interest.

\section{References}

1. Hu, M.; Skibsted, L.H. Antioxidative capacity of rhizome extract and rhizome knot extract of edible lotus (Nelumbo nuficera). Food Chem. 2002, 76, 327-333. [CrossRef]

2. You, J.S.; Lee, Y.J.; Kim, K.S.; Kim, S.H.; Chang, K.J. Ethanol extract of lotus (Nelumbo nucifera) root exhibits an anti-adipogenic effect in human pre-adipocytes and anti-obesity and anti-oxidant effects in rats fed a high-fat diet. Nutr. Res. 2014, 34, 258-267. [CrossRef] [PubMed]

3. $\mathrm{Xu}, \mathrm{S}$; Shoemaker, C.F. Gelatinization properties of chinese water chestnut starch and lotus root starch. J. Food Sci. 1986, 51, 445-449. [CrossRef]

4. $\mathrm{Xu}, \mathrm{Y}$. Perspectives on the 21st century development of functional foods: Bridging chinese medicated diet and functional foods. Int. J. Food Sci. Technol. 2001, 36, 229-242. [CrossRef]

5. Guo, H.B. Cultivation of lotus (Nelumbo nucifera Gaertn. Ssp. Nucifera) and its utilization in China. Genet. Resour. Crop Evol. 2008, 56, 323-330. [CrossRef]

6. Yang, D. Antioxidant Activities of Lotus Rhizome. Ph.D. Thesis, Zhejiang University, Hangzhou, China, 2007.

7. Tsuruta, Y.; Nagao, K.; Shirouchi, B.; Nomura, S.; Tsuge, K.; Koganemaru, K.; Yanagita, T. Effects of lotus root (the edible rhizome of Nelumbo nucifera) on the deveolopment of non-alcoholic fatty liver disease in obese diabetic db/db mice. Biosci. Biotechnol. Biochem. 2012, 76, 462-466. [CrossRef] [PubMed]

8. Mukherjee, D.; Khatua, T.N.; Venkatesh, P.; Saha, B.P.; Mukherjee, P.K. Immunomodulatory potential of rhizome and seed extracts of Nelumbo nucifera gaertn. J. Ethnopharmacol. 2010, 128, 490-494. [CrossRef] [PubMed]

9. Mukherjee, P.K.; Saha, K.; Pal, M.; Saha, B.P. Effect of nelumbo nucifera rhizome extract on blood sugar level in rats. J. Ethnopharmacol. 1997, 58, 207-213. [CrossRef]

10. Mukherjee, P.K.; Saha, K.; Balasubramanian, R.; Pal, M.; Saha, B.P. Studies on psychopharmacological effects of Nelumbo nucifera gaertn. rhizome extract. J. Ethnopharmacol. 1996, 54, 63-67. [CrossRef]

11. Yang, W.M.; Shim, K.J.; Choi, M.J.; Park, S.Y.; Choi, B.; Chang, M.S.; Park, S.K. Novel effects of Nelumbo nucifera rhizome extract on memory and neurogenesis in the dentate gyrus of the rat hippocampus. Neurosci. Lett. 2008, 443, 104-107. [CrossRef] [PubMed]

12. Sun, Y.; Zhang, W.; Zeng, T.; Nie, Q.; Zhang, F.; Zhu, L. Hydrogen sulfide inhibits enzymatic browning of fresh-cut lotus root slices by regulating phenolic metabolism. Food Chem. 2015, 177, 376-381. [CrossRef] [PubMed]

13. Zhang, S.; Yu, Y.; Xiao, C.; Wang, X.; Tian, Y. Effect of carbon monoxide on browning of fresh-cut lotus root slice in relation to phenolic metabolism. LWT-Food Sci. Technol. 2013, 53, 555-559. [CrossRef]

14. Wang, Q.; Pen, G.; Jin, Y.; Li, J.; Yan, S. Extraction of polyphenol from lotus roots and its enzymatic browning substrate. J. Anal. Sci. 2014, 20, 38-40.

15. Scalbert, A.; Manach, C.; Morand, C.; Rémésy, C.; Jiménez, L. Dietary polyphenols and the prevention of diseases. Crit. Rev. Food Sci. Nutr. 2005, 45, 287-306. [CrossRef] [PubMed]

16. Dai, J.; Mumper, R.J. Plant phenolics: Extraction, analysis and their antioxidant and anticancer properties. Molecules 2010, 15, 7313-7352. [CrossRef] [PubMed]

17. Guo, C.; Wei, J.; Yang, J.; Li, Y.; Xu, J.; Jiang, Y. The antioxidant capacity of 66 vegetables and fruits: A comparative study. Acta Nutr. Sinica 2003, 25, 203-207. 
18. Kaur, C.; Kapoor, H.C. Anti-oxidant activity and total phenolic content of some asian vegetables. Int. J. Food Sci. Technol. 2002, 37, 153-161. [CrossRef]

19. Chen, S.; Fang, L.; Xi, H.; Guan, L.; Fang, J.; Liu, Y.; Wu, B.; Li, S. Simultaneous qualitative assessment and quantitative analysis of flavonoids in various tissues of lotus (Nelumbo nucifera) using high performance liquid chromatography coupled with triple quad mass spectrometry. Anal. Chim. Acta 2012, 724, 127-135. [CrossRef] [PubMed]

20. Chen, S.; Zheng, Y.; Fang, J.; Liu, Y.; Li, S. Flavonoids in lotus (Nelumbo) leaves evaluated by hplc-ms ${ }^{\mathrm{n}}$ at the germplasm level. Food Res. Int. 2013, 54, 796-803. [CrossRef]

21. Huang, B.; Ban, X.; He, J.; Tong, J.; Tian, J.; Wang, Y. Hepatoprotective and antioxidant activity of ethanolic extracts of edible lotus (Nelumbo nucifera gaertn) leaves. Food Chem. 2010, 120, 873-878. [CrossRef]

22. Deng, J.; Chen, S.; Yin, X.; Wang, K.; Liu, Y.; Li, S.; Yang, P. Systematic qualitative and quantitative assessment of anthocyanins, flavones and flavonols in the petals of 108 lotus (Nelumbo nucifera) cultivars. Food Chem. 2013, 139, 307-312. [CrossRef] [PubMed]

23. Liu, Y.; Ma, S.; Ibrahim, S.A.; Li, E.; Yang, H.; Huang, W. Identification and antioxidant properties of polyphenols in lotus seed epicarp at different ripening stages. Food Chem. 2015, 185, 159-164. [CrossRef] [PubMed]

24. Jiang, Y.; Ng, T.B.; Liu, Z.; Wang, C.; Li, N.; Qiao, W.; Liua, F. Immunoregulatory and anti-hiv-1 enzyme activities of antioxidant components from lotus (Nelumbo nucifera gaertn) rhizome. Biosci. Rep. 2010, 31, 381-390. [CrossRef] [PubMed]

25. Sun, J.; Lu, S.S.; Xu, Y.; Min, T.; Wang, H.; Yi, Y. Comparison on the content, composition and antioxidant activity of phenolics among different parts of lotus root. J. Wuhan Polytech. Univ. 2015, 34, $20-25$.

26. Liu, H.; Cao, J.; Jiang, W. Evaluation and comparison of vitamin c, phenolic compounds, antioxidant properties and metal chelating activity of pulp and peel from selected peach cultivars. LWT-Food Sci. Technol. 2015, 63, 1042-1048. [CrossRef]

27. Li, W.; Liang, H.; Zhang, M.; Zhang, R.; Deng, Y.; Wei, Z.; Zhang, Y.; Tang, X. Phenolic profiles and antioxidant activity of litchi (Litchi chinensis Sonn) fruit pericarp from different commercially available cultivars. Molecules 2012, 17, 14954-14967. [CrossRef] [PubMed]

28. Xie, P.; Huang, L.; Zhang, C.; Zhang, Y. Phenolic compositions, and antioxidant performance of olive leaf and fruit (Olea europaea L.) extracts and their structure-activity relationships. J. Funct. Foods 2015, 16, 460-471. [CrossRef]

29. Zhang, M.W.; Zhang, R.F.; Zhang, F.X.; Liu, R.H. Phenolic profiles and antioxidant activity of black rice bran of different commercially available varieties. J. Agric. Food Chem. 2010, 58, 7580-7587. [CrossRef] [PubMed]

30. Jiang, J.; Jiang, L.; Luo, H.; Yu, Z. Establishment of a statistical model for browning of fresh-cut lotus root during storage. Postharvest Biolo. Technol. 2014, 92, 164-171. [CrossRef]

31. Li, Y. Studies on the technique of extract and purification and its anti-oxidant ability of tannin from nodes of lotus root. Master's Thesis, Huazhong Agricultural University, Wuhan, China, 2009.

32. Wood, L.G.; Gibson, P.G.; Garg, M.L. A review of the methodology for assessing in vivo antioxidant capacity. J. Sci. Food Agric. 2006, 86, 2057-2066. [CrossRef]

33. Khattak, K.F.; Simpson, T.J.; Ihasnullah. Effect of gamma irradiation on the microbial load, nutrient composition and free radical scavenging activity of Nelumbo nucifera rhizome. Radiat.Phys. Chem. 2009, 78, 206-212. [CrossRef]

34. Sánchez-Salcedo, E.M.; Mena, P.; García-Viguera, C.; Hernández, F.; Martínez, J.J. (poly)phenolic compounds and antioxidant activity of white (Morus alba) and black (Morus nigra) mulberry leaves: Their potential for new products rich in phytochemicals. J. Func. Foods 2015, 18, 1039-1046. [CrossRef]

35. Wang, X.; Li, C.; Liang, D.; Zou, Y.; Li, P.; Ma, F. Phenolic compounds and antioxidant activity in red-fleshed apples. J. Func. Foods 2015, 18, 1086-1094. [CrossRef]

36. Ti, H.; Guo, J.; Zhang, R.; Wei, Z.; Liu, L.; Bai, Y.; Zhang, M. Phenolic profiles and antioxidant activity in four tissue fractions of whole brown rice. RSC Adv. 2015, 5, 101507-101518. [CrossRef]

37. Lachman, J.; Hamouz, K.; Šulc, M.; Orsák, M.; Pivec, V.; Hejtmánková, A.; Dvořák, P.; Čepl, J. Cultivar differences of total anthocyanins and anthocyanidins in red and purple-fleshed potatoes and their relation to antioxidant activity. Food Chem. 2009, 114, 836-843. [CrossRef]

38. Singleton, V.L.; Orthofer, R.; Lamuela-Raventós, R.M. Analysis of total phenols and other oxidation substrates and antioxidants by means of folin-ciocalteu reagent. Methods Enzymol. 1999, 299, 152-178. 
39. Zhishen, J.; Mengcheng, T.; Jianming, W. The determination of flavonoid contents in mulberry and their scavenging effects on superoxide radicals. Food Chem. 1999, 64, 555-559. [CrossRef]

40. Brand-Williams, W.; Cuvelier, M.E.; Berset, C. Use of a free radical method to evaluate antioxidant activity. LWT-Food Sci. Technol. 1995, 28, 25-30. [CrossRef]

41. Benzie, I.F.F.; Strain, J.J. The ferric reducing ability of plasma (frap) as a measure of "antioxidant power": The frap assay. Anal. Biochem. 1996, 239, 70-76. [CrossRef] [PubMed]

Sample Availability: Samples of the phenolic extracts from lotus roots are available from the authors.

(C) 2016 by the authors; licensee MDPI, Basel, Switzerland. This article is an open access article distributed under the terms and conditions of the Creative Commons Attribution (CC-BY) license (http://creativecommons.org/licenses/by/4.0/). 